\title{
Expression of Defense Responsive Gene in Rice after the Infection of Rhizoctonia solani
}

\author{
Raja Husain ${ }^{1}$, N.A. Khan", A. Mishra', M.K. Sharma ${ }^{2}$ A. Singh², R.S. Sengar ${ }^{2}$, \\ M.K. Yadav', Vinay K. Yadav', Jaygendra Kumar', Harishchandra', \\ K. Gyanendra ${ }^{1}$, Shivani ${ }^{1}$, N. Vikram ${ }^{3}$, and K.N. Singh ${ }^{1}$ * \\ ${ }^{1}$ Department of Plant Molecular Biology and Genetic Engineering, Narendra Deva University of \\ Agriculture and Technology Kumarganj Faizabad (U.P.) India \\ ${ }^{2}$ Department of Agriculture Biotechnology, Sardar Vallabhbhai Patel University of Agriculture \\ and Technology, Meerut (U.P.) India \\ ${ }^{3}$ Department of Biochemistry, Zila Parishad Agriculture College, Banda (U.P.) India \\ *Corresponding author
}

\section{Keywords \\ Sheath blight, SES, 8 A1, 4C7, R. solani. \\ Article Info \\ Accepted: \\ 29 June 2017 \\ Available Online: \\ 10 July 2017}

\section{A B S T R A C T}

Rice sheath blight, caused by Rhizoctonia solani is one of the major diseases of rice. The pathogen infects rice plants directly through stomata or using lobate appressoria and hyphal masses called infection cushions. Initially the mycelium looked thread like structure, milky white in colour than mycelium converted mature Sclerotia. After the screening of different rice genotypes using 0 to 9 scaling (SES-IRRI), according to Leaf detach method, Pusa Basmati-1 was found highly susceptible variety and Swarna sub-1 was susceptible one. Among wild rice, O. australiensis was observed resistant species, while Oryza rufipogon was found moderately resistant species. Approximately the same results were found in humidified chamber condition. During molecular analysis, In control condition, 8A1 gene/primer was not expressed in Pusa Basmati-1 and Swarna sub-1, it was expressed in stressed condition in both the cultivar with the product size $155 \mathrm{bp}$. In both wild rice namely $O$. rufipogon and $O$. australiensis, $8 \mathrm{~A} 1$ gene was expressed in control as well as stressed condition with the product size $155 \mathrm{bp}$. While $4 \mathrm{C}_{7}$ gene/primer was expressed continuously in control and stressed condition in susceptible rice cultivars; Pusa Basmati-1, Swarna sub-1 and wild rice accessions- $O$. rofipogon and $O$. australiensis with the product size $162 \mathrm{bp}$.

\section{Introduction}

Rice sheath blight, caused by the fungal pathogen Rhizoctonia solani Kuhn [Sexual stage: Thanetophorus cucumeris (Frank) Donk] is one of the major production constraints in rice-growing countries of the world. Currently, the best method for controlling sheath blight is applying commercial fungicides. Breeding for sheath blight resistant rice plants has not been very successful mainly because of lack of resistant donors in the cultivated varieties of rice (Bonmann et al., 1992).

Rice sheath blight is a necrotrophic disease. Consequently, very little is known about the host-fungus interaction at the molecular level. As a first step to define the defense-related gene expression profile, we first observed the 
infection process of the pathogen and the corresponding expression pattern of the pathogenesis-related genes, $P R 1 b$ and $P B Z 1$ (Midoh and Iwata, 1996). The most common resistance reaction in plants is the hypersensitive response (HR), which localizes the pathogen at the infection site through cell death. The local responses at the point of infection also trigger a subsequent nonspecific resistance that occurs throughout the entire plant; this phenomenon is called systemic acquired resistance (SAR). Typical SAR results in an increase of endogenous salicylic acid (SA) and transcriptional activation of defense-related genes including pathogenesis-related genes $P R 1, P R 2$ and $P R 5$ etc. It finally leads to an enhanced resistance to a broad spectrum of pathogens throughout the plant (Ryals et al., 1996; Durrant and Dong, 2004). The HR typically occurs in the diseases caused by biotrophic pathogens, in which defence signaling is initiated by $\mathrm{R}$ protein-Avr protein interactions, and many of these pathways require SA (Denby et al., 2004).

There is no resistance in cultivated rice varieties, however; some level of resistance to sheath blight $(\mathrm{ShB})$ was reported in Jasmine, Tequing, NDR 2030, and Giri (Sinha et al., 2004). The resistance reaction of different wild rice accessions can be transferred to adopted genetic background of cultivated rice (Prasad and Eizenga, 2008; Nelson et al., 2011). Different rice accessions including 15 Oryza species belonging to $\mathrm{O}$. australiensis, O. minuta and O. officinalis were found resistant/moderately resistant to $\mathrm{ShB}$ and sheath rot and transferred in cultivated rice for ShB resistance (Lakshmanan, 1991; AmanteBordeos et al., 1992; Ritu and Goel, 2007).

\section{Materials and Method}

The present investigation was carried out at the Net house and laboratory of Department of Plant Molecular Biology and Genetic Engineering, Narendra Deva University of Agriculture and Technology, Kumarganj, Faizabad (U.P.) India. During the Kharif season of 2013-14 and 2014-15. The experiment was laid out in a complete randomized design (CRD) and randomized complete block design (RCBD) in pots (Net house) condition with three replications. The details of materials used, experimental procedures fallowed and protocols are given below:

\section{Plant Materials}

Seeds of rice and wild rice were collected/ procured from NBPGR, Pusa, New Delhi and C.R.R.I Cuttack, Orissa (M.P) and Department of Genetics and Plant Breeding, N.D. University of Agriculture and Technology, Kumarganj, Faizabad India.

\section{$R$. solani isolates}

A multinucleate compatible, highly virulent strain of $R$. solani, D-14 belonging to AG1-IA anastomosis group was obtained from the Rice Pathology Laboratory, G.B. Pant University of Agriculture and Technology, Pantnagar, U.K. India. This isolate was grown on Potato dextrose Agar at $28+1^{\circ} \mathrm{C}$ for 6 days and used as the inoculation purpose.

\section{Screening of resistance by detached leaf methods}

Five week old leaves of different hosts and non hosts were cut in the size of $9 \mathrm{~cm}$ long and kept in plastic-dishes. Inoculation was made aseptically at the centre of a leaf by placing a $5 \mathrm{~mm}$ mycelia agar disc from a four days old culture of $R$. solani grown on PDA plates as described by Galindo et al., (1982). After inoculation, proper moist condition was maintained inside the plastic Petri-dishes using three fold what man filter paper 
saturated with sterile double distilled water. There were three leaves per Petri-dishes, replicated three times for each of the hosts. 72 Hrs. after inoculation, the severity of leaf infection was rated following 0 to 9 scales (Jia et al., 2002), scale with 0 having no lesion to 9 having 90 to $100 \%$ of the leaf surface covered with lesions.

\section{Humidified chamber condition}

Inoculation procedure for infection in cultivated varieties of rice and wild rice by $R$. solani isolates was performed according to Park et al., (2008). Immature sclerotia developed on 4-6 days Old mycelia of $R$. solani strain D-14 was grown on Potato Dextrose Agar (PDA) medium. An immature sclerotium of $R$. solani was placed underneath the leaf sheath with $10 \mathrm{ml}$ of sterilized water. Inoculated and non-inoculated plants were placed in humidified chamber condition at $28 \pm 1^{\circ} \mathrm{C}$ for $24 \mathrm{hrs}$. Scoring of disease was carried out on 0-9 rating scale (Standard Evalution System of IRRI) as described below:

$0=$ absolutely free from infection

$1=$ lesions limited to lower $20 \%$ of plant height

$3=20-30 \%$ disease

$5=31-45 \%$ disease

$7=46-65 \%$ disease

$9=$ more than $65 \%$ disease.

\section{Inoculation of different hosts for RNA isolation}

Inoculation of the different hosts plants for the total RNA isolation purpose were done in the humid chamber condition. The non inoculated control plant was also served as negative control condition which placed in the humidified chamber. Leaves were harvested from the non inoculated (control) and inoculated plants after 72 hours. of inoculation. The harvested leaves were briefly rinsed with in sterile distilled water, dried with paper towel, put immediately in mortar pestle and crushed in the presence of liquid nitrogen and stored in the deep freezer ($\left.80^{\circ} \mathrm{C}\right)$.

\section{Isolation of total RNA}

Collected the fresh leaves of rice in ice container from infected and (control) non infected plants and ground $100 \mathrm{mg}$ leaves sample in liquid nitrogen in fine powder with the help of mortar and pestle. Transferred the powder into autoclaved Eppendorf tubes and added $1 \mathrm{ml}$ trizol buffer solution mix the content by shaking. Incubate the tube 2-3 minutes at room temperature $\left(20-30^{\circ} \mathrm{C}\right)$. Centrifuged the sample at $9000 \mathrm{rpm}$ for 10 minute at $4{ }^{\circ} \mathrm{C}$ and transferred the supernatant into a new sterile centrifuge tube and discard the pellet. $200 \mu \mathrm{l}(0.2 \mathrm{ml})$ of chloroform was added into the tube and Mixed vigorously and stored the tube for 2-3 $\mathrm{min}$ at room temperature. Centrifuged and transferred the upper aqueous layer to a fresh tube. The RNA was precipitated by adding 0.5 volume of isopropanol and 0.5 volume of RNA ppt. solution. Stored the tubes for 10 minutes at room temperature and recovered the RNA by centrifugation at $9000 \mathrm{rpm}$ for 10 minute at 4 ${ }^{\circ} \mathrm{C}$.

\section{Analysis of transcript levels by reverse transcriptase-mediated PCR}

To analyze the expression patterns of these genes during the interaction with $R$. solani, RT-PCR analysis was conducted. Total RNA was reverse-transcribed into first-strand cDNA with oligo-dT primer according to kit protocol (Genei two step MMLV-RT-PCR kit) and the cDNA was used as a template for PCR to analyze the selected genes. The primers for the PCR were designed based on the sequences of the genes (Table 1). Two 
primers namely $8 \mathrm{~A}_{1}$ and $4 \mathrm{C}_{7}$ were amplified using the control and stressed cDNA template. Following condition was standardized for the amplification of genes with different primers which was performed by using thermal cycler (PTC-100, Bio-Rad, USA).

$\left.\begin{array}{llccc}\text { Stage } & \text { Step } & \text { Temp }\left({ }^{\circ} \mathbf{C}\right) & \text { Duration } & \text { No. of cycle } \\ 1 & \text { Initial denaturation } & 94 & 4 \mathrm{~min} . & \\ 2 & \text { Denaturation } & 94 & 1 \mathrm{~min} . \\ 3 & \text { Annealing (vary with temp) } & 55 & 1.5 \mathrm{~min} . \\ 4 & \text { Extension } & 72 & 2 \mathrm{~min} . \\ 5 & \text { Total extension } & 94 & 10 \mathrm{~min} . \\ 6 & \text { Storage } & 4 & \end{array}\right\}$

\section{Results and Discussion}

analyze the selected genes. In present experiment, In control condition, 8A1 gene/primer was not expressed in Pusa Basmati-1 and Swarna sub-1, it was expressed in stressed condition in both the varieties with the product size 155 bp. While 8A1 gene/primer was expressed in both wild rice namely $O$. rofipogon and $O$. australiensis in both control as well as stressed condition with the product size $155 \mathrm{bp}$ (Fig. 4).

In control condition, $4 \mathrm{C}_{7}$ gene/primer was expressed continuously in both control and stressed condition in both susceptible rice varieties; Pusa Basmati-1 and Swarna sub-1 with the product size 162 bp. $4 \mathrm{C}_{7}$ gene/primer was expressed in both wild species namely $O$. rofipogon and $O$. australiensis in both condition control as well as stressed condition with the product size 162 bp (Fig. 4). However, the roles of ethylene insensitive- 3like protein (4C7), translationally controlled tumor protein (9B12) and oxygen-evolving enhancer protein 2 (8B2) in response to pathogens are unknown.

\section{Analysis of transcript levels by reverse transcriptase-mediated PCR}

Total RNA was isolated using trizol method (Fig. 3) and reverse-transcribed into firststrand cDNA with oligo-dT primer and the cDNA was used as a template for PCR to

Rice sheath blight disease is an important fungal disease of rice, which has become a major constraint to rice production during the last two decades (Kobayashi et al., 1997). A highly virulent strain of $R$. solani, D-14 belonging to AG1-IA anastomosis group was 
colonized into black brown. Initially the mycelium looked thread like structure, milky white in colour than mycelium converted mature Sclerotia. Sunder et al., (2003) had also reported that colony colour ranged from brown, light brown, dark brown and yellowish brown. The results are also supported by Hoa (1994), reported that sclerotial colour ranged from brown, light/dark brown, black brown, chocolate brown, salmon and dark salmon.

In the past, IRRI developed the standard evaluation system for rice sheath blight disease based on relative lesion length, which is the average vertical height of the uppermost lesion expressed as a percentage of the average plant height (IRRI. 2002). According to Leaf detach method, using 0 to 9 scaling, Pusa Basmati-1 was found highly susceptible variety and Swarna sub-l was found susceptible one. Among wild rice, $O$. australiensis was observed resistant species. While Oryza rufipogon was found Moderately
Resistant species. Approximately the same results were found in humidified chamber condition (Table 2, Figures 1 and 2). The similar results were found by Shamim et al., 2014, they screened 52 rice cultivar in humidified chamber condition, leaf detach condition and field condition against sheath blight and observed that Kalanamak, Pusa Basmati, Swarna, IR-64 were found the susceptible cultivar while $O$. australiensis and $O$. grandiglumis were found the resistance. Prasad et al., (2008), reported that the detached-leaf inoculation method separated cvs. Jasmine 85 and TeQing, moderately resistant checks, from Lemont and Cocodrie, highly susceptible checks, based on disease reaction (lesion length). Eizenga et al., (2002), used the toothpick method/ humidified chamber method to evaluate disease intensity based on the leaf lesion length of both the leaf blade and sheath summed together. Data from the first three leaves were useful in interpreting disease response as reported earlier.

Table.1 The primers for the PCR

\begin{tabular}{|l|l|l|l|}
\hline $\begin{array}{l}\text { Gene/ } \\
\text { primer }\end{array}$ & Forward primer & Reverse primer & $\begin{array}{l}\text { Annealing } \\
\text { temperature } \\
\left({ }^{\circ} \mathbf{C}\right)\end{array}$ \\
\hline 4C7 & 5-CCAATTCGAGCCGTCAT-3 & 5-CAGCAGCAGTTCTTCATCC-3 & 55 \\
\hline $\mathbf{8 A 1}$ & 5-GTGGTCCAATAGAGTGATGC-3 & 5-AGAGACATACCAATTGCAGG-3 & 55 \\
\hline
\end{tabular}

Table.2 Screening of resistance by detached leaf methods/ Humidified chamber condition

\begin{tabular}{|c|c|c|c|c|c|c|}
\hline \multirow{2}{*}{$\begin{array}{c}\text { Rice varieties / } \\
\text { sps. }\end{array}$} & \multicolumn{3}{|c|}{ Leaf detach method } & \multicolumn{3}{|c|}{ Humidified chamber condition } \\
\hline & \begin{tabular}{|l|l}
$0-9$ \\
scaling
\end{tabular} & Disease \% & Categories & \begin{tabular}{|l|}
$0-9$ \\
scaling
\end{tabular} & Disease \% & Categories \\
\hline Pusa Basmati-1 & 9 & $>90 \%$ & HS & 9 & $>75 \%$ & HS \\
\hline Swarna sub-1 & 7 & $<65 \%$ & $\mathrm{~S}$ & 7 & $<85 \%$ & HS \\
\hline Oryza rufipogon & 5 & $45 \%$ & MR & 5 & $40 \%$ & MR \\
\hline O. australiensis & 1 & $<20 \%$ & $\mathrm{R}$ & 1 & $<20 \%$ & $\mathrm{R}$ \\
\hline
\end{tabular}

Note: HS- Highly susceptible; S- Susceptible; MR- Moderately Resistant

R- Resistant 
Fig.1 Disease symptoms of sheath blight, a- $R$. solani culture plate, b- inoculated or infected rice plant, c- leaf of $O$. australiensis, d- leaf of Swarna sub-1
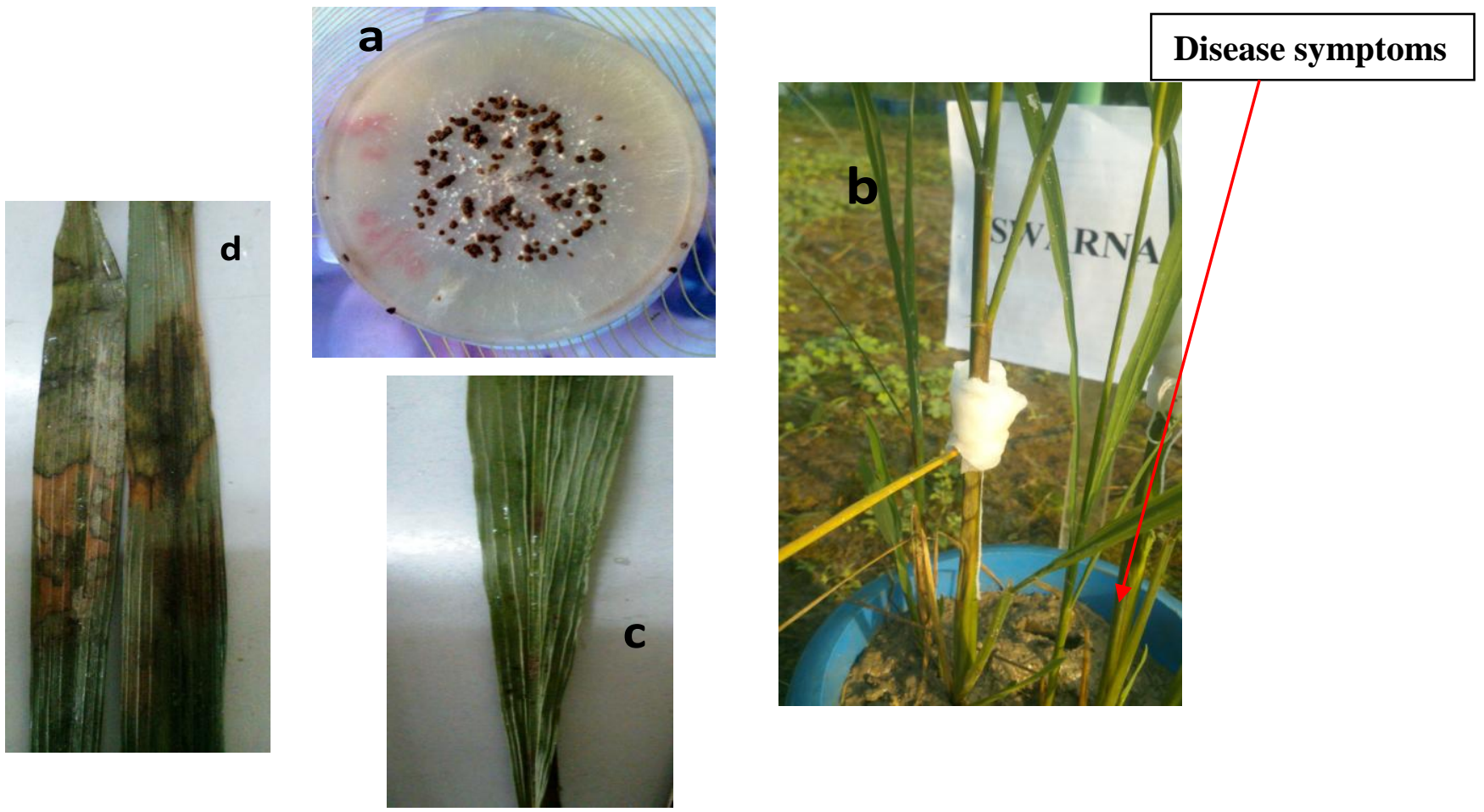

Fig.2 Disease symptoms of sheath blight on (a) Pusa Basmati-1 and (b) O. australiensis under leaf detach method condition

\section{Disease symptoms}

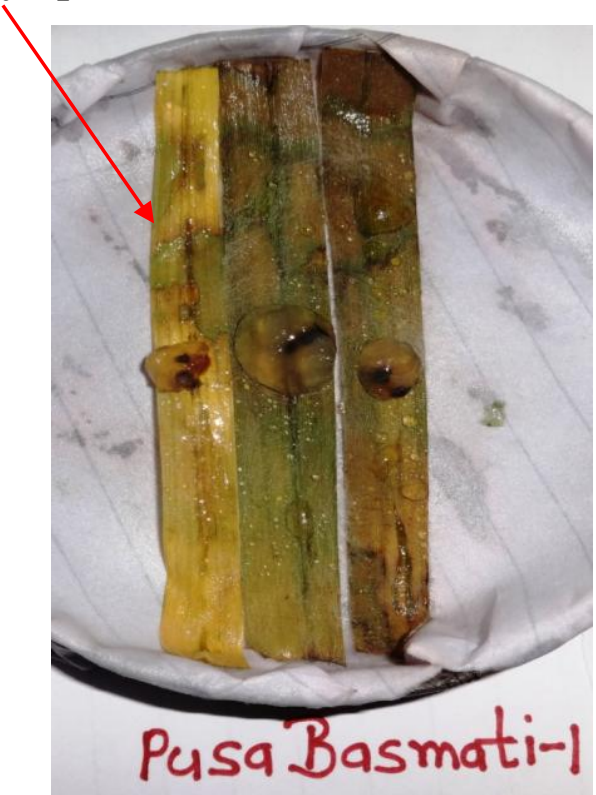

(a)

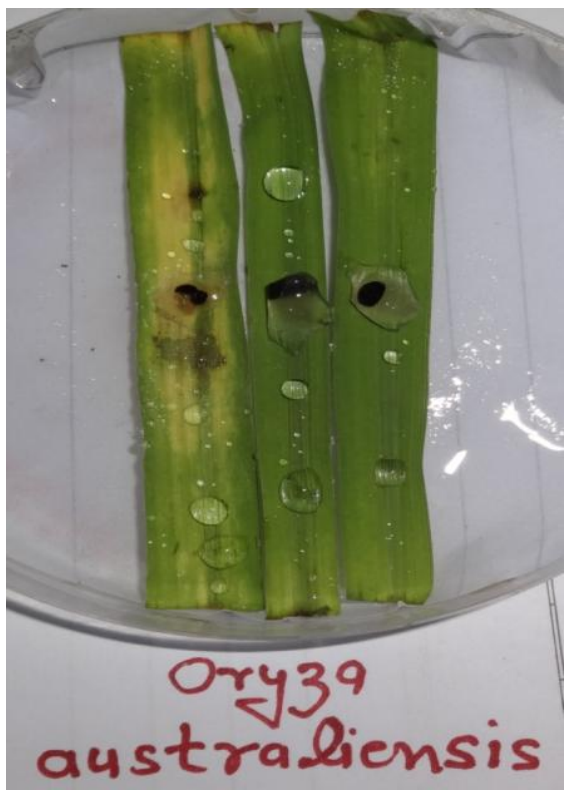

(b) 
Fig.3 RNA Gel Electrophoresis of Different rice cultivar at $1.2 \%$ Agarose

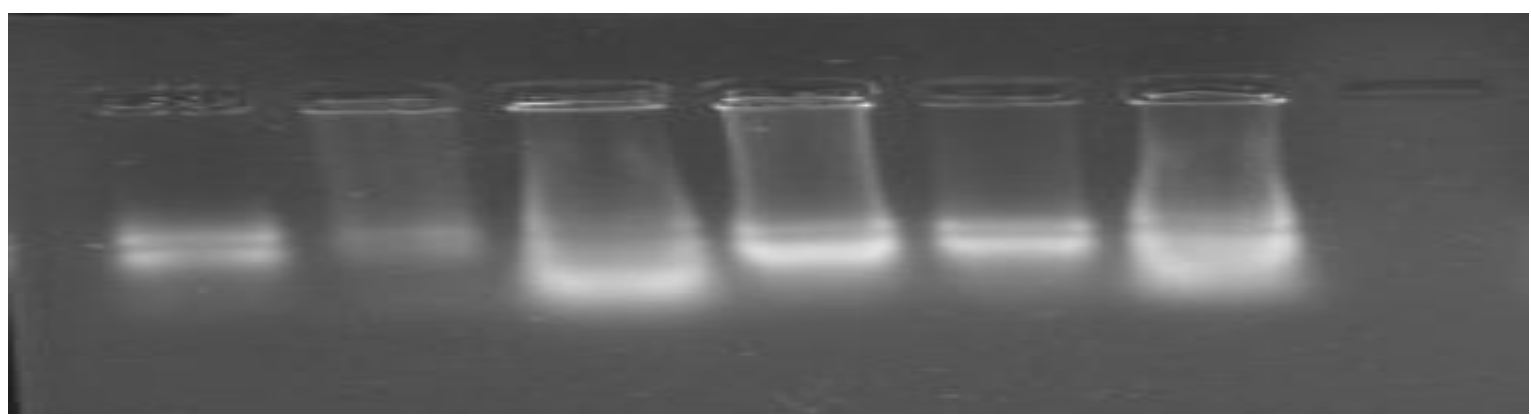

Fig.4 PCR with 8 A1 primer M- Marker(100bp), 1 \& 2-Pusa Basmati-1, 3 \& 4- Swarna sub-1, 5 \& 6- O. rufipogon, 7\& 8- O. autraliensis

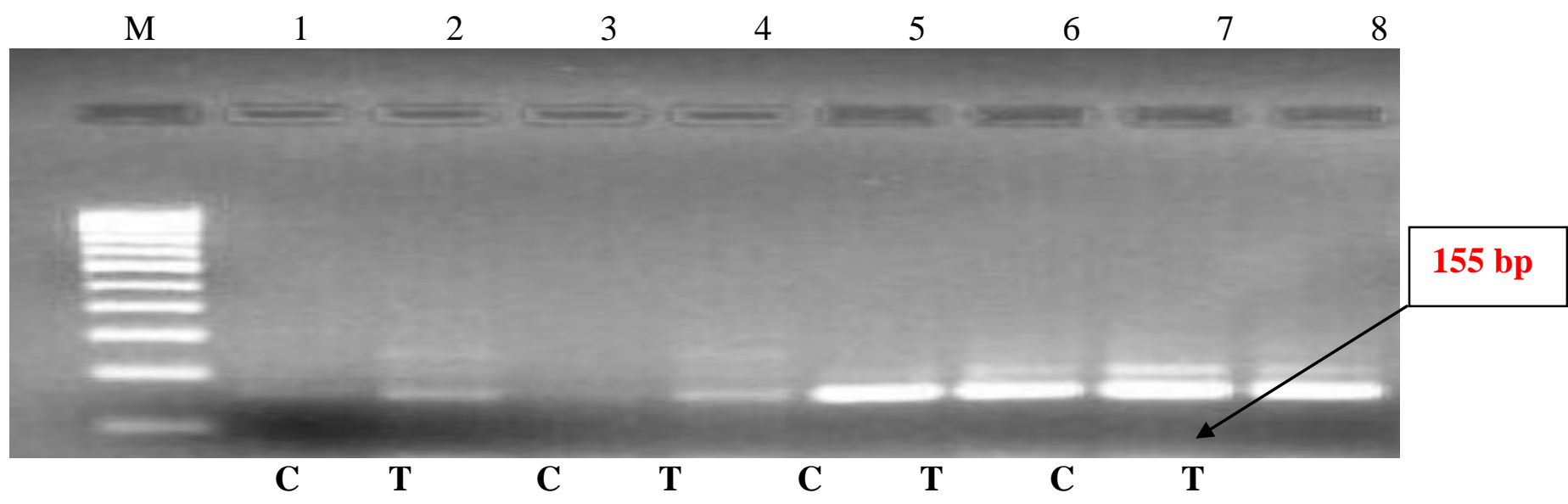

Fig.5 PCR with 4 C7 primer, M- Marker(100bp), 1 \& 2-Pusa Basmati-1, 3 \& 4- Swarna sub-1, 5 \& 6- O. rufipogon, 7\& 8-O. autraliensis. C- Control, T- Treated

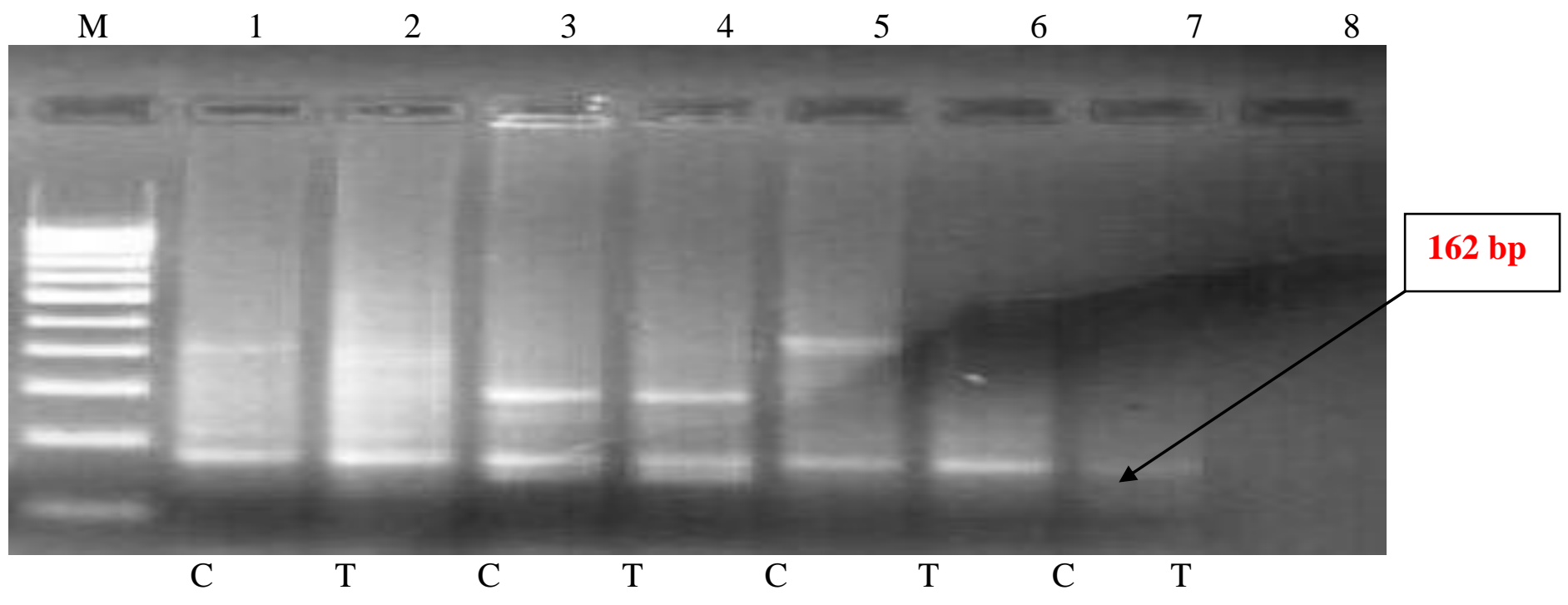


During molecular analysis, 8A1 gene/primer was not expressed in Pusa Basmati-1 and Swarna sub-1 in control condition, it was expressed in stressed condition in both the varieties with the product size $155 \mathrm{bp}$. While 8A1 gene/primer was expressed in both wild rice namely $O$. rofipogon and $O$. australiensis in all condition with the product size $155 \mathrm{bp}$. The similar results were found by Zhao et al., 2008 for both gene 8 A1 and 4C7. According to the gel analysis of PCR product of their experiment, 8A1 was not expressed initially, it was expressed after $24 \mathrm{hrs}$ of infection. While 4C7 expressed in control as well as treated condition. Further characterization of 8 A1 gene may shed light on the relationship between the ubiquitination pathway and the defense response in plants. It is interesting to note that $8 \mathrm{~A} 1$ encodes a putative ubiquitinconjugating enzyme E2. The ubiquitin /proteasome pathway is the major selective protein degradation system in eukaryotes. Growing evidence indicates that this pathway plays an important role in plant defense responses (Dreher and Callis, 2007).

In control condition, $4 \mathrm{C}_{7}$ gene/primer was expressed continuously in both control and stressed condition in both rice varieties; Pusa Basmati-1 and Swarna sub-1 with the product size 162 bp. $4 \mathrm{C}_{7}$ gene/primer was expressed in both wild rice namely $O$. rofipogon and $O$. australiensis in both condition as well as stressed condition with the product size 162 bp. However, the roles of ethylene insensitive- 3-like protein (4C7), translationally controlled tumor protein (9B12) and oxygen-evolving enhancer protein 2 (8B2) in response to pathogens are unknown.

In conclusion, rice sheath blight caused by R.solani is one of the most common diseases in rice. Pusa Basmati-1 and Swarna sub-1 observed the susceptible varieties after screening in Humidified chamber condition and leaf detach condition using the SES-IRRI protocol. Among wild rice, O. australiensis was observed resistant species, while Oryza rufipogon was found moderately resistant sps. During molecular analysis, 8A1 gene/primer was not expressed in control condition in Pusa Basmati-1 and Swarna sub-1, while 8A1 gene was expressed in control as well as stressed condition in both wild rice accessions $O$. rofipogon and $O$. australiensis. Another $4 \mathrm{C}_{7}$ gene was expressed continuously in control and stressed condition in all rice cultivar. So 8A1 gene acts as a defense responsive gene which is induced in stressed condition.

\section{Acknowledgements}

The First author is gratefully acknowledge to NBPGR, New Delhi and CRRI, Cuttack, Orissa, India, for providing wild rice accessions and cultivated rice varieties for conducting the present study and also acknowledge to Dr. R.S. Sengar, Prof. and Head and Dr. M.K. Yadav, Assistant Professor, Department of Agricultural Biotechnology, S.V.P.U.A\& T, Meerut, U.P., India for providing necessary facilities to complete the molecular work.

\section{References}

Amante-Bordeos, A., Sitch, L.A., Nelson, R., Dalmacio, R.D., Oliva, N.P., Aswidinnoor, H. and Leung, H. 1992. Transfer of bacterial blight and blast resistance from the tetraploid wild rice Oryza minuta to cultivated rice, Oryza sativa. Theor. Appl. Genet., 84: 345354.

Bonmann, J.M., Khush, G.S. and Nelson, R.J.1992. Breeding rice for resistance to pests. Annu. Rev. Phytopathol., 30: 507-523.

Denby, K.J., Kumar, P. and Kliebenstein, D.J. 2004. Identification of Botrytis cinerea susceptibility loci in Arabidopsis thaliana. Plant J., 38: 473-486

Durrant, W.E. and Dong, X. 2004. Systemic acquired resistance. Annu. Rev. Phytopathol., 42:185-209. 
Eizenga, G.C., Lee, F.N. and Rutger, J.N. 2002. Screening Oryza species plants for rice sheath blight resistance. Plant Dis., 86: 808812.

Galindo, J.J., Abawi G.S. and Thurston, H.D.1982. Variability among the isolates of Rhizoctonia solani associated with snap bean hypocotyls and soils in New York. Plant Dis., 66: 390-394.

Hoa, T.T.C. 1994. Characterization and pathogenicity of Rhizoctonia solani Kuhn isolates from different rice zone and management of sheath blight of rice. Ph.D Thesis, Indian Agricultural Research Institute, New Delhi-12, p. 122.

IRRI. 2002. Standard evaluation system for rice (SES). International Rice Research Institute, Manila, Philippines.

Jia, Y., Singh, P., Eizenga, G.C., Lee, F.N. and Cartwright, R.D. 2002. In vitro identification of cultivar responses to rice sheath blight pathogen Rhizoctonia solani. In: Wells BR (ed) Rice research studies 2002. Arkansas Agricultural Experiment Station research series 504. Arkansas Agricultural Experiment Station, Fayetteville, pp 229-236.

Kobayashi, T., Mew, T.W., Hashiba, T. 1997. Relationship between incidence of rice sheath blight and primary inoculum in the Philippines: Mycelia in plant debris and sclerotia. Ann. Phytopathol. Soc. Jpn., 63: 324-327.

Lakshmanan, P. 1991. Resistance to sheath blight $(\mathrm{ShB})$ and brown spot (BS) in lines derived from Oryza officinalis. Int. Rice Res. Newsl., 16: 8 .

Midoh, N. and Iwate, M. 1996. Cloning and characterization of a probenazole- inducible gene for an intracellular pathogenesis-related protein in rice. Plant Cell Physiol., 37: 9-18.
Nelson, J., Oard, J.H., Groth, D., Utomo, H., Jia, Y., Liu, G., Moldenhauer, K.K., CorreaVictoria, F.J., Fjellstrom, R.G., Scheffler, B.E. and Prado, G.A.2011. Sheath blight resistance QTLs and in japonica rice germplasm. Euphytica, 184: 23-24.

Park, D.S., Sayler, R.J., Hong, Y.G., Nam, M.H. and Yang, Y.2008. A method for inoculation and evaluation of rice sheath blight disease. Plant Dis., 92: 25-29.

Prasad, B. and Eizenga, G.C.2008. Rice Sheath Blight Disease Resistance Identified in Oryza spp. Accessions. Plant Dis., 92: 1503-1509.

Ritu, B. and Goel, R.K. 2007. Detection of sources of multiple disease resistance in different Oryza species. J. Res., 44: 110-112.

Ryals, J.A., Neuenschwander, U.H., Willits, M.G., Molina, A., Steriner, H.Y. and Hunt, M.D.1996. Systemic acquired resistance. Plant Cell, 8: 1809-1819.

Shamim, Md., Kumar, D., Srivastava, D., Pandey, P., Singh, K.N. 2014. Evaluation of major cereal crops for resistance against Rhizoctonia solani under green house and field conditions, Indian Phytopath., 67(1): 42-48.

Sinha, S.K., Sen, S.N. and Biswas, A. 2004. Giri a high yielding, slender grain, sheath blight and bacterial blight resistant variety for shallowwater conditions in West Bengal. Int. Rice Res. Newsl., 29: 17.

Sunder, B., Kataria, H.R., Satyavir and Sheoran, O.P. 2003. Characterization of Rhizoctonia solani associated with root/collar rots and blights. Ind. Phytopathol., pp. 27-33.

Zhao, C.J., Wang, A.R., Shi, Y.J., Wang, L.Q., Liu, W.D., Wang, Z.H.and Lu, G.D.2008. Identification of defense-related genes in rice responding to challenge by Rhizoctonia solani. Theor. Appl. Genet., 116: 501-516.

\section{How to cite this article:}

Raja Husain, N.A. Khan, A. Mishra, M.K. Sharma, A. Singh, R.S. Sengar, M.K. Yadav, Vinay K. Yadav, Jaygendra Kumar, Harishchandra, K. Gyanendra, Shivani, N. Vikram, and Singh, K.N. 2017. Expression of Defense Responsive Gene in Rice after the Infection of Rhizoctonia solani. Int.J.Curr.Microbiol.App.Sci. 6(7): 4201-4209.

doi: https://doi.org/10.20546/ijcmas.2017.607.435 